\title{
Postrimerías de un ingeniero de Su Majestad: el testamento de Bautista Antonelli
}

\author{
Margarita-Ana Vázquez-Manassero
}

Universidad Nacional de Educación a Distancia (UNED), Madrid, España, mavazquez@geo.uned.es

\begin{abstract}
The engineer Bautista Antonelli's (Gatteo, c.1545 - Madrid, 1616) unpublished testament is a precious document as its terms reveal interesting information about his biographical and professional features. On the one hand, Bautista's constant and strong professional awareness runs throughout the document due to his own lifelong dedication and his sense of belonging to a family of military engineers. On the other hand, this testament allows an analysis of the links that Bautista kept in the twilight of his life with certain places (Madrid, Gatteo, Alicante and Havana), as well as mapping his relationships with some important personalities of the time such as the engineer Antón Coll or Antonio de Herrera, who was secretary of Vespasian Gonzaga. Summing up, the testament sheds light on the complex figure of Bautista, reveals new biographical and professional aspects and contributes to a better understanding of his poliorceticon work in the Mediterranean and American areas.
\end{abstract}

Keywords: Bautista Antonelli, testament, military engineering, Antonio de Herrera.

\section{IntroducciónEl 18 de febrero de 1616 el ingeniero del rey Felipe III, Bautista Antonelli (Gatteo, c. 1545 - Madrid, 1616), otorgó carta de testamento en la villa de Madrid "estando enfermo de la enfermedad que dios $n r s^{r}$ fue seruido de me dar" (AHPM, Prot. 2989, fol. 271 r.) ${ }^{1}$}

En el estado actual de los conocimientos en torno a la figura de Bautista Antonelli, este documento aporta nuevas informaciones sobre los aspectos que la historiografía reciente coincide en señalar como los más desconocidos de este ingeniero: los detalles biográficos y la actividad profesional desarrollada en el ocaso de sus días (Sartor, 2004).

Así, su testamento, inédito hasta la fecha, se revela como un precioso documento en el que bajo las cláusulas del mismo se recogen interesantes aspectos tanto biográficos como profesionales.
2. Consideraciones en torno a la profesión de ingeniero contenidas en el testamento de Bautista Antonelli

En primer lugar, debe destacarse cómo la marcada conciencia profesional de Bautista va a ser una constante que recorre todo el documento. En este sentido, debe tenerse en cuenta que la carrera profesional del menor de los Antonelli se desarrolla fundamentalmente a lo largo de las tres últimas décadas del siglo XVI y los primeros quince años del XVII, un momento determinante en la configuración de la imagen profesional de los ingenieros militares caracterizado por el debate entre ciencia y experiencia en el que se hallaba inmersa la profesión. En este contexto, Bautista Antonelli dejará patente en reiteradas ocasiones en su testamento la dignidad que le confería el ostentar un cargo de tal relevancia como era el de Ingeniero del Rey, dependiente del Consejo de Guerra, y que garantizaba unos ingresos fijos y 
duraderos además de otra serie de ventajas, como la concesión de ayudas de costa cuando debían desplazarse por su trabajo (Cámara, 1981).

Conscientes de la importancia de ocupar un puesto de tanta categoría, los Antonelli, tanto Juan Bautista como Bautista, quisieron dejar constancia del elevado status profesional y de la dignidad del oficio que ejercieron en vida en sus respectivas sepulturas. Así, el mayor de los Antonelli, ordena enterrarse en la sepultura que tiene comprada en la capilla mayor del madrileño monasterio de San Francisco, indicando que en ella se había colocado su escudo de armas y debajo de él, "un letrero que dice esta sepultura es de Juan bautista antoneli ingeniero militar del Rey don felipe nuestro señor para el y sus herederos año de mill y quinientos y ochenta y siete" (Toro, 1936, p.47). De un modo análogo, en las postreras voluntades de Bautista - quien aquí nos ocupa - queda más que patente su marcada consciencia profesional que se verá reflejada en las mandas testamentarias que a continuación van a ser objeto de análisis.

En primer lugar, ordena ser enterrado con el hábito del Carmen en sepultura propia en el convento de San Hermenegildo de Madrid. En cuanto a la sepultura, Bautista precisa que debe ser "lo mas cercana al altar mayor que pudiere ser y que se ponga enzima della vna piedra con vn letrero que diga aqui está sepultado el capitan bap ${ }^{a}$ antoneli ingeniero militar de el Rey nro $s^{r}$ y debajo del letrero mis armas que son las que entrego al pres ${ }^{e}$ escriu para que las de a mis albazeas en vn patron de papel pintadas" (AHMP, Prot. 2989, fols. 271 r.- 271 v.). Con esta declaración, parece evidente que Bautista Antonelli tuvo especial cuidado a la hora de dar orden a sus albaceas de cómo debía ser su sepultura, en cuya inscripción debía constar su nombre y categoría profesional y fue él mismo quien realizaría la traza de su escudo de armas.

Esta misma voluntad de perpetuar su nombre y la vinculación del mismo a la profesión que ejerció al servicio de la monarquía hispánica es aún más manifiesta si cabe en las precisiones contenidas en su testamento relativas a la fundación de un depósito de trigo para socorrer a los pobres en su villa natal, Gatteo. En ellas, se especifica que de los "seiscientos y veynte cinco ducados de a onze reales castellanos" que lega para la creación del depósito de trigo para socorrer a las viudas y huérfanas naturales o vecinas de dicha villa del obispado de Rímini, se deberán destinar veinticinco ducados de los restantes para hacer un granero. Lo interesante en relación con la cuestión de la consideración social de la imagen del ingeniero es que el granero donde habría de conservarse el trigo, en primer lugar, debía situarse en un lugar preeminente de la villa - la plaza pública de San Lorenzo - para que fuera visto y admirado por todos sus convecinos (AHPM, Prot. 2989, fol. 273 v.). En segundo lugar, Bautista ordena que sobre su puerta debía colocarse un escudo de mármol y un letrero en la forma siguiente:

"enzima de la puerta se ponga vn escudo de mármol y en el mis armas y debajo de las dhas armas vn letrero tanbien [de] mármol que diga en lengua italiana ansi este deposito de trigo para pobres mando hazer el capitan $\mathrm{Ju}^{\theta}$ bap $^{a}$ antoneli ingeniero militar de los Serenissimos Reyes de España don Phelipe segundo y terzero [...]" (AHPM, Prot. 2989, fols. 273 v. - 274 r.)

De este modo, queda patente, de un lado, la estrecha vinculación que Bautista mantenía con su villa natal al final de sus días, a pesar de que su longeva existencia hubiera transcurrido alejado de ella, recorriendo los confines del orbe. Por otro lado, el modo de presentarse y autorrepresentarse ante sus convecinos como fundador de una importante obra pía pone de manifiesto su propia consciencia en torno a la profesión de ingeniero así como de la elevada dignidad que le otorgaba el haber desempeñado su oficio al servicio de los monarcas Felipe II y Felipe III.

Por otra parte, en relación con el texto transcrito unas líneas más arriba es interesante apuntar que el escribano que redactaba el testamento, erró y nombró al otorgante, por un momento, Juan Bautista, en lugar de Bautista. A falta de conocer a qué razones puede obedecer este error - tal vez porque apenas unas líneas más arriba del documento el escribano acaba de nombrar al 
mayor de los Antonelli -, lo cierto es que este dato nos habla posiblemente de la secular confusión que se ha venido produciendo en la historiografía a la hora de identificar a Juan Bautista y Bautista Antonelli.

Otra de las constantes que se advierten en el testamento de Bautista Antonelli es el sentimiento de pertenencia y vinculación familiar a una saga de ingenieros militares. Es significativo que nada más comenzar el documento se declare hermano de Juan Bautista Antonelli "difunto y ansimismo ingeniero militar que fue de su mag",. De la admiración y la relación que mantuvo con su hermano mayor tenemos otros testimonios documentales. Una buena muestra del valor que otorgaba Bautista a los logros profesionales alcanzados por su hermano mayor la encontramos en una carta que Bautista dirige al rey para referir lo que vio y ordenó desde La Habana a México. En ella comenta lo siguiente: "Mi zelo es acertar en el servicio de V.M., y caminar por las pisadas de mi hermano Juan Bautista Antonelli" (Llaguno, 1829, p.252).

Asimismo, Bautista en su voluntad de perpetuar el oficio familiar en su primogénito - Juan Bautista, a quien declara su legítimo heredero y sucesor - pide al rey en su testamento tomar en consideración los cerca de cincuenta años en que estuvo al servicio de la monarquía como ingeniero, realizando numerosas fortificaciones, para que hiciera merced a su hijo quien por aquel entonces desempeñaba idéntica ocupación en Cartagena de Indias, "para que con mayor decencia pueda continuar y continue el acudir y ocuparse en su real seruicio" (AHPM, Prot. 2989, fol. 276 r.). Poco después, Bautista ordena a sus testamentarios le hagan llegar a su hijo los libros, trazas, papeles e instrumentos de su profesión con una clara finalidad: transmitir a su vástago los conocimientos adquiridos durante su dilatada trayectoria, de gran relevancia, teniendo en cuenta que uno de los rasgos que distinguió la labor de estos ingenieros militares fue la experiencia adquirida sobre el terreno y la práctica de la fortificación.
3. El testamento como cartografía de un recorrido vital: vínculos $y$ relaciones personales de Bautista Antonelli al final de sus días

En otro orden de cosas, el documento que aquí está siendo objeto de estudio permite trazar un mapa de los vínculos que Bautista Antonelli mantenía al final de su vida con determinados lugares. Se ha referido con anterioridad a su relación con la villa de Madrid y la orden de los Carmelitas Descalzos y con la villa de Gatteo que le vio nacer. A este respecto, a tenor de lo contenido en su testamento es preciso notar que el ingeniero romagnolo debió mantener a lo largo de su vida, cierto vínculo con la costa levantina. Así, Bautista dispone en su testamento que se den treinta ducados a las monjas de Santa Verónica de Alicante "para ayuda a pagar vn ornamento de terciopelo carmesí para las fiestas de $s^{t}$ Lorenzo" (AHPM, Prot. 2989, fol. 274 v.). Son conocidas las referencias a la profunda religiosidad de que debió dar muestras Bautista ${ }^{2}$, quien estando en Madrid en 1585, viéndose "perseguido, pobre y aburrido" debió plantearse ingresar como fraile (Llaguno, 1829, p. 59) y la relación con las monjas de Santa Verónica de Alicante - llamado en realidad Monasterio de la Santa Faz - debe remontarse al periodo en que el ingeniero trabajó en el Reino de Valencia a finales de la década de 1570 y demuestra su querencia por ese reino.

Otra de las localizaciones en las que Bautista desarrolló una parte importante de su actividad profesional y que aparece referenciada en sus últimas voluntades es La Habana. En su testamento deja constancia de que todavía en el fin de sus días se le debían mil ducados "de la industria y trauajo que fue sitiar el agua de la chorrera a la habana los quales me prometio el maese de campo $\mathrm{J} u^{o}$ de Tejada de carta de su mag. ${ }^{d}$ gobernador que fue de aquella isla i [...] de la dha ciudad como parecerá por los papeles presentados en poder del s. ${ }^{r}$ secretario çiriça en tiempo que fue del cons ${ }^{\circ}$ de yndias" (AHPM, Prot. 2989, fol. 276 r.)

De la reclamación del pago de los trabajos realizados por Bautista en $\mathrm{La}$ Chorrera de $\mathrm{La}$ Habana tenemos ya constancia documental en 
1593. En ese año, con fecha de 23 de septiembre, el que fuera protector de Antonelli el secretario Juan de Ibarra - envía una misiva al rey en favor del ingeniero. En ella, además de informar al monarca del estado de necesidad y de tristeza de ánimo por el que atravesaba el ingeniero, le reclama que se le acreciente el sueldo, se le pague lo que gastó en el viaje a Honduras y, en tercer lugar, "que sin tela de juicio se le manden pagar los mil ducados que le ofreció Tejada de parte del Havana porque fuese el agua de la Chorrera" (Llaguno, 1829, pp.267-268). Sin embargo, parece que la petición de Ibarra de que se le pagara a Antonelli las cantidades correspondientes a los trabajos de La Chorrera debieron ser desoídas y, aún en sus últimos días, continuaba reclamando la cantidad que en su día le había prometido en maese de campo Tejada.
Un último aspecto a analizar, pero que sin embargo, es la que podría considerarse como la aportación más interesante que puede extraerse del testamento de Bautista Antonelli estriba en las relaciones ya sea profesionales como personales - si bien en muchos casos ambas cuestiones se entrelazan - que mantuvo Bautista $\mathrm{y}$ que quiso dejar recogidas en sus postreras voluntades.

En cuanto a las menciones a otros ingenieros, además de las ya citadas referencias a los miembros de la saga Antonelli, hay que destacar la deuda contraída con el también ingeniero Antón Coll de quien dice que por aquel entonces residía en la Isla Tercera y a quien debe veinticinco escudos que le prestó. Son pocas las noticias documentales relativas a Antón Coll recogidas por la historiografía.

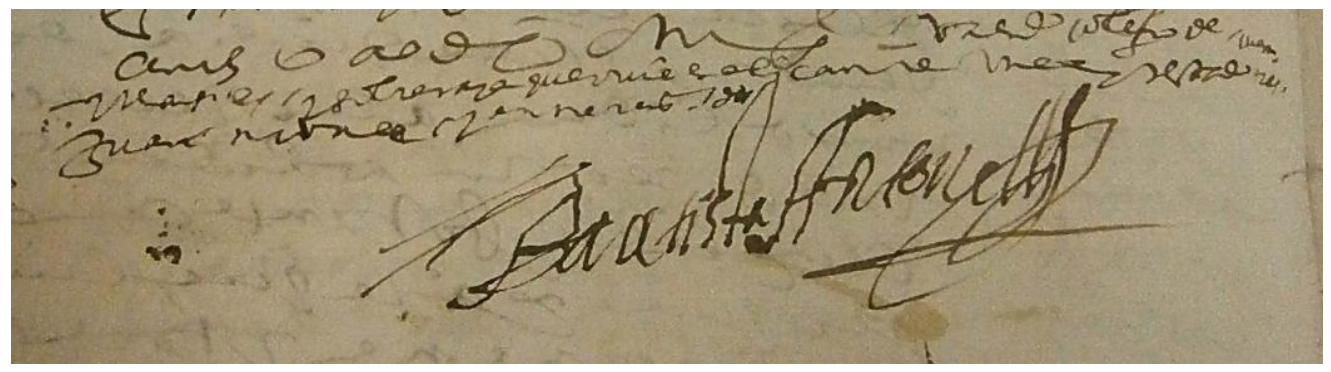

Fig. 1- Firma de Bautista Antonelli, contenida en su testamento (AHPM, Prot. 2989, fol. 278 v.)

De él se sabe que fue maestro de obras de confianza de Calvi y que trabajó ocho años con Juan Bautista Antonelli y otros quince con el capitán Fratín. Su colaboración con estos renombrados ingenieros consistió fundamentalmente en preparar "los papeles $y$ modelos que hazían". Asimismo, fue maestro mayor de las obras de los castillos de San Juan de Lisboa y de San Felipe en Setúbal, visitando dichos fuertes en 1587. Más adelante, en 1594, Antón Coll fue enviado a la fortificación de la Montaña de Brasil en la Isla Tercera (Cámara, 1998). Éstas son las escasas noticias documentales referidas en la historiografía que dan cuenta de la cronología de la trayectoria profesional de Coll. A falta de más datos relativos a este ingeniero, si tenemos en cuenta que en el testamento de Antonelli de 1616 se le sitúa todavía en la Isla Tercera y se ordena que la deuda habría de ser abonada a sus familiares, por hallarse ausente; podemos plantear dos hipótesis: o bien que Antón Coll habría permanecido ininterrumpidamente desde 1594 en la Isla Tercera, o bien que, pudiendo haberse desplazado a otros lugares en el intervalo de tiempo comprendido entre $1594 \mathrm{y}$ 1616 , en esta última fecha, las labores constructivas emprendidas en dicha Isla todavía continuarían en curso. Por otra parte, a pesar de que en el testamento no se especifica la naturaleza de la deuda contraída por Bautista con Antón Coll, esta noticia atestigua que debió existir relación entre ambos y que ésta seguramente se remontaría al periodo en que el segundo colaboró con su hermano mayor, Juan Bautista ${ }^{3}$. 
Más interesante si cabe resulta el análisis de las relaciones mantenidas por Bautista Antonelli con aquellas personalidades que nombra como testamentarios y albaceas encargados de cumplir y ejecutar las últimas voluntades contenidas en el documento testamentario: Antonio de Herrera, quien fuera secretario de Vespasiano Gonzaga y cronista mayor de Indias del monarca católico; María de Torres, esposa de Herrera; Jacome Ferraro, secretario del duque de Módena y residente por aquel entonces en la ciudad de Madrid y, por último, el padre prior que estuviere en el Monasterio de San Hermenegildo de los Carmelitas Descalzos en el momento de su defunción (AHPM, Prot. 2989, fol.278 r.).

En cuanto al primero de sus testamentarios, Antonio de Herrera ${ }^{4}$, es importante señalar para comprender la naturaleza de la relación que trabaría con Bautista Antonelli, la relevancia de que el futuro cronista estando en Italia ingresara al servicio del príncipe Vespasiano Gonzaga Colonna (1532-1591) a partir de 1570 (Cuesta, 2009). Más adelante, tras el nombramiento de Gonzaga como Virrey de Navarra en 1571, Antonio de Herrera regresaría a España acompañando al príncipe italiano y posteriormente, cuando recibió el cargo de Virrey de Valencia (1574-1578), Herrera continuaría gozando de la confianza de este príncipe. Por su parte, Bautista Antonelli debió conocer a Vespasiano Gonzaga durante la jornada de Orán ${ }^{5}$ en la que acompañó a su hermano mayor (Llaguno, 1829). En este sentido, todo apunta a que Gonzaga seguramente debió ser el nexo de unión entre Antonio de Herrrera y el pequeño de los hermanos Antonelli y que el encuentro entre ambos se habría producido durante la década de 1570 .

En la prolija producción literaria de Herrera queda más que patente que este cronista debió poseer amplios conocimientos de poliorcética y cosmografía como aparece claramente reflejado en sus obras ${ }^{6}$. En este sentido, hay que destacar su "Discurso y tratado que será más útil para la defensa y seguridad de los Reynos y Estados las fortalezas bien presidiadas o los exercitos en campaña y milicias bien ordenadas" (Herrera, s. XVIII) ${ }^{7}$. En este discurso, Herrera aborda la cuestión del Arte de fortificar y esgrime los inconvenientes y provechos que la construcción de fortalezas acarrean a los reinos, concluyendo que "las fortalezas son muy neçesarias en los estados y principalmente en los Mediocres $Y$ mucho más en los que tienen muchos confines y fronteras como la Corona de España pues no puede tener en todas partes exerçitos formados y por tanto el mucho cuidado $Y$ gasto q ahora se pone en las fortificaciones no puede dexar de ser loado y aprouado de quien bien $Y$ derechamente Lo quisiere entender [...]" (Herrera, s. XVIII, fols. 35 v.-36 r.). Con respecto a la relación que Bautista Antonelli mantuvo con Herrera, es interesante señalar que, si bien a lo largo del mencionado discurso alude a un gran número de fortalezas de diferentes épocas y ámbitos geográficos - lo que sin duda prueba su erudición en la materia -, por el contrario, no especifica quienes fueron los artífices encargados de proyectar estas obras de arquitectura militar, con una excepción: el ingeniero Bautista Antonelli, a quien refiere en los siguientes términos:

“[...] La Resistencia q[ue] se hiço a los Ingleses sobre Puerto Rico saluo aquellos Millones y ellos hiçieron despues poco fruto al Conde de el lugar que sedio para que llegase Don Bernardino de Avellaneda con su Armada que los hecho de las Indias maltratados. La fortificaçion q[ue] se hiço en la angostura de la Sierra de capira por consejo del ingeniero Bautista Antoneli saluo de los Ingleses el Reyno de tierra firme y los tesoros q[ue] estauan en Panama y si Santo Domingo y Cartaxena estuuieran fortificadas no fueran saqueadas" (Herrera, s. XVIII, fol. 32 r.)

La precisa descripción que el cronista proporciona sobre una de las fortalezas proyectadas por Bautista en Panamá se refiere a la defensa organizada por los españoles tras el ataque del pirata Francis Drake ocurrido en el año de 1596 en esas costas. Ante el peligro que suponía dicha incursión, Bautista - quien por aquel entonces se encontraba en Panamá acudió a la defensa del río Chagre y construyó el fuerte de San Pablo en el cerro, que llaman Caparilla, en la angostura del camino de Portobelo a Panamá, lo que obligó a la retirada de los ingleses (Llaguno, 1829, pp. 64-65). 
Pero la referencia a Bautista en sus "Discursos..." no es la única mención que en la documentación generada por el cronista hallamos al ingeniero y parece claro que la relación entre ambas personalidades debió mantenerse hasta el fin de sus respectivas vidas. De hecho, en el testamento de Antonio de Herrera, otorgado a 15 de marzo de 1622 , el apodado "príncipe de los cronistas" mandaba que, tras su fallecimiento, su cuerpo fuera depositado en el convento de San Hermenegildo de Carmelitas descalzos de Madrid donde estaba enterrado el capitán Bautista Antonelli y del que él era patrón (Pérez, 2006). Además, es preciso apuntar brevemente que Herrera también mantuvo contacto con otros miembros de la familia Antonelli estando en vida Bautista. En este sentido, Ballesteros-Beretta en su prólogo a la "Descripción de las Indias..." señala la existencia de un poder notarial otorgado a 8 de febrero de 1605 por Herrera al capitán García de Heredia, a fin de que perciba 200 ducados que un Cristóbal de Roda, residente en La Habana, envía a Esteban Adargo, de Santander, Criado de $\mathrm{Su}$ Majestad, "para ciertos efectos", y en su ausencia a Herrera (Herrera, 1934, p.XL). Ese indeterminado Cristóbal de Roda que menciona Ballesteros-Beretta no era otro que el sobrino de Bautista Antonelli, llegado a La Habana en 1591 para ayudar a su tío - por aquel entonces enfermo - para dirigir los trabajos del Morro y La Punta, y cuya estancia en la isla se prolongaría hasta 1608 (Sartor, 2004). Así, nuevamente, nos encontramos al cronista como intermediario de los intereses de los Antonelli en la corte.

Por el contrario, tanto las noticias documentales relativas a otro de sus testamentarios como las referencias a su persona en la historiografía reciente resultan mucho más exiguas. Nos referimos a Jacome Ferraro a quien en el testamento de Bautista Antonelli se refiere como "secretario del duque de modena". En el transcurso de la presente investigación, únicamente se ha tenido conocimiento de dos documentos en los se refiere a este personaje. El primero, y más significativo de ellos es el ya citado testamento del mayor de los Antonelli, Juan Bautista. Al dictar sus últimas voluntades en 1588 nombra junto al genovés Sebastián Lercaio y a Juan Gil, a "Xacome ferrari secretario del duque de ferrara en esta corte" como albaceas y testamentarios encargados de ejecutar las mandas y pías causas contenidas en el documento testamentario. De este modo, parece demostrado que las relaciones entre Jacome Ferraro y, por ende, de la corte de Ferrara con la familia Antonelli se remontarían a la década de 1580 y se habrían mantenido y prolongado hasta la muerte del menor de los ingenieros ${ }^{8}$.

El segundo documento notarial en el que figura un tal "Xacome Ferrera" cuyo cargo es asimismo el de secretario de la duquesa de Módena parece confirmar que, si bien la relación entre Ferrari y Bautista Antonelli debió ser intermitente dadas las dilatas ausencias de la corte del ingeniero, ésta debió mantenerse a lo largo de toda su vida. El documento al que nos referimos es un "poder notarial del capitán Bautista Antonelli, ingeniero militar de S.M. para cobrar ciertas cantidades del abad de San Benito de Valladolid y de Antonio de Herrera cronista del Rey y Xacome Ferrera, secretario de la Duquesa de Modena" otorgado en Valladolid a 27 de marzo de 1602 (AHPM, Prot. 1662, fol. 587). Por aquel entonces, Bautista todavía permanecía en América por lo que parece lógico que otorgara un poder a dos personas cercanas para que cobraran ciertas cantidades en su nombre.

En el estado actual de la investigación en torno a las relaciones diplomáticas entre las cortes de España y de Ferrara de las últimas décadas del siglo XVI y la primera mitad del siglo XVII parece difícil delimitar cuál debió ser el papel ejercido por el citado secretario del duque de ferrara (después, duque de Módena). Al calor de los datos aquí aportados, parece claro que Jácome Ferraro, quien en 1588, residía en Madrid y, en 1602, en Valladolid, debió hacer las veces de representante diplomático primero, del duque de Ferrara, y después del duque de Módena - Cesare d'Este - en la corte española, estando primero en Madrid $\mathrm{y}$, trasladándose junto con la misma a Valladolid, ya en tiempos de Felipe III. En relación con Bautista Antonelli, su vinculación a este personaje del que pocos 
son los datos que conocemos, debió ejercer si no como su protector, al menos como intermediario de sus intereses y personaje cercano en la corte.

\section{Conclusiones}

A modo de conclusión, con todo lo expuesto, el análisis del testamento del que fuera ingeniero de los reyes Felipe II y Felipe III, ha permitido por un lado, profundizar en aspectos como la conciencia profesional que los propios ingenieros del Renacimiento tenían de su oficio. Así lo demuestran las instrucciones que Bautista Antonelli da a la hora de colocar tanto en su sepultura como en el depósito de trigo que funda para socorrer a los pobres en su villa natal, sendos letreros en los que se especifica su categoría profesional de ingeniero militar al servicio de la monarquía hispánica. Todo ello, son indicadores de una fuerte identidad como profesión así como un reflejo de la importancia social que la misma fue adquiriendo en esa época. En este sentido, también destaca su sentimiento de pertenencia y vinculación a una saga familiar de ingenieros, en las referencias a su hermano mayor y el legado de los instrumentos propios de su oficio a su hijo.Por otra parte, el estudio de este documento testamentario ha permitido trazar un mapa más preciso de algunas de las relaciones tanto personales como profesionales que Bautista mantuvo hasta el ocaso de sus días con determinados lugares como Madrid, Gatteo, Alicante o La Habana, así como trazar un mapa de sus relaciones con algunas relevantes personalidades de la época, como el también ingeniero Antón Coll, o los que serían sus testamentarios: el reputado cronista Antonio de Herrera y el menos conocido Jácome Ferrari (o Ferrera, según el documento), secretario del duque de Módena. La relación de Bautista Antonelli con estos dos últimos se prolongaría desde la década de 1580 hasta el ocaso de sus días y, teniendo en cuenta las largas ausencias del ingeniero de la corte, parece probable que tanto Herrera como Ferrari, habrían podido mediar o defender en cierta manera los intereses de Bautista en el entorno cortesano. De este modo, el análisis de las cláusulas y mandas contenidas en el testamento de este ingeniero de
Su Majestad arroja luz sobre la compleja figura de Bautista Antonelli, dando a conocer nuevos aspectos biográficos y profesionales que contribuirán a la mejor comprensión de su obra poliorcética tanto en el ámbito del Mediterráneo como Americano.

\section{Notas}

(1) Este trabajo ha sido realizado gracias al contrato predoctoral FPI (BES-2013-062631) dentro del Proyecto de Investigación HAR201231117 "El dibujante ingeniero al servicio de la Monarquía Hispánica. Siglos XVI-XVIII” del Ministerio de Economía y Competitividad. Agradezco a la Dra. Alicia Cámara sus enriquecedores comentarios sobre este trabajo.

(2) En su testamento Bautista Antonelli da prueba en reiteradas ocasiones de su piedad: además de su estrecha vinculación a los carmelitas descalzos ordenando ser enterrado con el hábito de dicha orden, manda asimismo que se gasten en el acompañamiento, entierro y misas cien escudos a disposición de sus albaceas. Además, Bautista manda para ayuda a la canonización de San Isidro de Madrid cuatro ducados de a once reales castellanos (AHPM, Prot. 2989, fol. 271 v.)

(3) La deuda viene expresada del modo siguiente: "Yten declaro que no me acuerdo deuer nada a nadie excepto a Anton col ingeniero que reside en la isla tercera que le deuo veynte cinco escudos que me presto de a onze reales mando se le paguen a sus parientes" (AHPM, Prot. 2989, fol. 271 v.)

(4) Sobre la biografía de Herrera véase la introducción de Antonio Ballesteros-Beretta a Herrera (1934) y la breve biografía incluida en Cuesta (2009). Para la producción literaria de Herrera como cronista, véase Kagan (2005).

(5) Para conocer la imagen de la ciudad de Orán y la fortificación de Mazalquivir que Vespasiano Gonzaga visitó en compañía de Juan Bautista Antonelli, véase Cámara (2010).

(6) Un buen ejemplo de la erudición del cronista en materia de cosmografía y navegación lo encontramos en su Descripción de las Indias Orientales (Herrera, 1934). 
(7) El mss. 3011 de la BN (Madrid) es una copia del manuscrito original de Herrera realizada por Fernando de Vallejo, quien deja su firma en el fol. 189. Sin embargo, Vallejo no deja constancia del año preciso en que fue copiado. De ahí que, en el Inventario general de manuscritos de la Biblioteca Nacional, vol. IX (2815 a 3026) se sitúe cronológicamente el manuscrito en el siglo XVIII. Asimismo, el discurso al que hacemos referencia en el texto aparece reproducido en los Discursos morales, políticos e históricos inéditos de Don Antonio de Herrera publicados en Madrid por D. Juan Antonio de Zamácola en 1804.
(8) Sartor (2004, p.45) en relación con la fecha de regreso a España de Bautista de su segundo viaje a América (c. 1586-1588), comenta que se desconoce la fecha exacta en que el ingeniero regresa pero aporta un testimonio documental interesante, según el cual Bautista, junto con un tal Jácome Ferrari, certificaba la muerte de su hermano mayor, Juan Bautista, el 19 de marzo de 1588, esto es, dos días después de tuviera lugar su fallecimiento. A tenor de lo que aquí se ha expuesto parece lógico que ese "tal Jácome Ferrari" certificara la defunción de Juan Bautista, pues había sido nombrado testamentario del mismo.

\section{Referencias}

Archivo Histórico de Protocolos de Madrid (AHPM), Testamento del ingeniero Bautista Antonelli, otorgado en Madrid a 18 de febrero de 1616, Prot. 2989, fols. 271 r.-278 v.

Archivo Histórico de Protocolos de Madrid (AHPM), Poder del capitán Bautista Antonelli, ingeniero militar de S.M. para cobrar ciertas cantidades del abad de San Benito de Valladolid y de Antonio de Herrera cronista del Rey y Xacome Ferrera, secretario de la Duquesa de Modena, otorgado en Valladolid a 27 de marzo de 1602, Prot. 1662, fol. 587.

Cámara A. (1981). "La arquitectura militar y los ingenieros de la monarquía española: aspectos de una profesión 1530-1650)”, en Revista de la Universidad Complutense, nº 3, pp. 255-269.

Cámara, A. (1998). Fortificación y ciudad en los reinos de Felipe II. Nerea Ed. Madrid. pp.81, 112.

Cámara, A., Moreira, R., Viganò, M. (coords.) (2010). Leonardo Turriano ingeniero del rey. Fundación Juanelo Turriano Ed. Madrid. pp. 49-117, 227-282.

Cuesta M. (2009). Antonio de Herrera y Tordesillas. Historiador acreditado. Caja Segovia Ayuntamiento de Cuéllar Eds. Cuéllar. 241 p.

Herrera, A. (siglo XVIII). Primera parte de las varias epístolas, discursos y tractados a diuersos claros varones, las quales contienen muchas materias útiles para el gouierno político y militar, con un Elogio de la vida y hechos de el Lizenciado Christoual Vaca de Castro, del Consejo Supremo y Gouernador de los Reynos del Piru. Biblioteca Nacional. Madrid. Mss/3011. fols. 27r.- 36r.

Herrera, A. (1934). Historia general de los hechos de los castellanos en las islas y tierra firme del mar océano por Antonio de Herrera publicada por acuerdo d la Academia de la Historia. Tomo I. Descripción de las Indias Orientales con prólogo y notas del académico de número Antonio Ballesteros-Beretta. Real Academia de la Historia Ed. Madrid. pp. I-LXXXVIII.

Kagan, R.L. (2005). Los cronistas y la corona. La política d la historia en España en las Edades Media y Moderna. Centro de Estudios Europa Hispánica-Marcial Pons Eds. Madrid. pp. 181-282.

Llaguno E. (1829). Noticias de los arquitectos y arquitectura de España desde su restauración, tomo III. Imprenta Real Ed. Madrid. pp. 58-66.

Pérez, C. (2006). "Testamento de Antonio de Herrera", en Boletín de la Real Academia de Historia, tomo 25, 1894. Edición digital Biblioteca Virtual Miguel de Cervantes. pp. 305-312.

Sartor M. (2004). "Omaggio agli Antonelli. Considerazioni intorno tre generazioni di architetti militari italiani attivi nel Mediterraneo e in America" en Omaggio agli Antonelli. Forum Ed. Udine. pp. 2368.

Toro L. (1936). “Juan Bautista Antonelli, El Mayor” en Boletín de la Real academia Sevillana de Buenas Letras: Minervae Baeticae, $n^{\circ}$, pp. 41-56. 